\title{
Yüksek pH Dayanımlı Yeni Tip Demir Şelat Formülünün Hazırlanması ve Yerfıstığı Ïzerine Etkilerinin İncelenmesi
}

\author{
İlyas GÖNÜL ${ }^{* 1}$, Anıl DELIIKANLI ${ }^{1}$, Selahattin SERİN ${ }^{1}$ \\ ${ }^{1}$ Çukurova Üniversitesi, Fen Edebiyat Fakültesi, Kimya Bölümü, Adana
}

$\ddot{\mathbf{O} z}$

Geliş tarihi: 19.07.2019 Kabul tarihi: 30.09 .2019

Bu çalışmada daha ucuz olan sitrik asit ve trietanolamin gibi ligandlarla oluşturulan demir şelatının yüksek pH'lardaki kararlılıkları incelenmiştir. Bitkiler için önemli bir besin elementi olan demir, kireçli ve yüksek $\mathrm{pH}$ değerine sahip topraklarda suda çözünmeyen demir hidroksit veya demir karbonat bileşiklerini oluşturarak bitkiler için yararsız hale gelmektedir. Demir iyonunun bitki bünyesine alınması ve bitkilerdeki demir iyonu eksikliğinin giderilmesi bu iyonun suda çözünür formda olmasıyla mümkündür. Bitki bünyesine demir iyonunun alınmaması veya yetersiz alınması bitkinin demir eksikliği klorozu olmasına neden olmaktadır. Ülkemiz topraklarında rahatlıkla kullanılabilen demir şelat çözeltisi hazırlanmış ve bu demir şelat çözeltisinin NC-7 ve ÇOM yerfıstığı çeşitlerinin büyümesi üzerindeki etkileri incelenmiştir.

Anahtar Kelimeler: Demir eksikliği klorozu, Demir şelatı, NC-7 ve ÇOM yerfıstı̆̆ı, Yüksek pH'lardaki kararlılık

\section{Preparation of New Type Iron Chelate Formula with High pH Resistance and Investigation of its Effects on Peanut}

\begin{abstract}
In this study, the preparation of iron chelate solution by using ligands such as citric acid and triethanolamine, which are cheaper, and their stability at high $\mathrm{pH}$ were investigated. Iron which is an important nutrient for plants is becoming useless for plants by forming water-insoluble iron hydroxide or iron carbonate compounds in soils having a high $\mathrm{pH}$ and chalky. Receiving a plant body of iron ions and elimination of iron ion deficiency in plants is possible with that it is in water-soluble form of this iron ion. Not receiving the iron ion to plant body or inadequate intake causes to which is becoming Iron deficiency chlorosis of the plant. The iron chelate solution which is comfortably usable in the soil of our country were prepared and the effects of this iron chelate solution on the growth of NC-7 and ÇOM peanut varieties were investigated.
\end{abstract}

Keywords: Iron deficiency chlorosis, Iron chelate, NC-7 and ÇOM peanut, High pH stability

*Sorumlu yazar (Corresponding author): İlyas GÖNÜL, ilyasgonul01@gmail.com 


\section{GíRiș}

Demir, yer kabuğunda en bol bulunan ve çok çeşitli sektörlerde kullanılan çok önemli bir metaldir. Her yıl Dünya demir üretiminin yarısına yakını korozyon yolu ile heba olmaktadır. Korozyona uğramış veya hurdaya çıkmış demirlerden ve demir yüzey temizleme işlemlerinden ortaya çıkan atıklardan demir bileşikleri üretilebilmektedir. Yine titandioksit üretim tesislerinde yan ürün olarak demir bileşikleri oluşmakta ve dünya pazarlarında satılmaktadır. Demir (II) sülfat çimento katkısı olarak ve su arıtma sistemlerinde floklaştırıcı olarak, demir şelatları gübre olarak kullanılmaktadır. Demir (II) sülfat'ın önemli bir kısmı, demir şelatlarının ise tamamı ithal yollarla temin edilmektedir.

Demir (II) sülfat tetrahidrat $\left(\mathrm{FeSO}_{4} \cdot 4 \mathrm{H}_{2} \mathrm{O}\right)$ kristalleri dört sulu olarak üretilmekte ve çimento sektöründe krom (VI)'yı krom (III)'e indirgemek için kullanılmaktadır. Ancak demir sülfatın heptahidrat hali çimento sektöründe kabul görmemekte olup, kısmen kurutulup k1smen de katkılandırılarak kullanıma sunulmuş hali tercih edilmektedir.

Demir, hemen hemen tüm canlı organizmaların büyümesi ve hayatta kalması için en önemli unsurdur [1]. Yosun gibi organizmaların sitokrom ve katalaz gibi enzimler ile hemoglobin ve miyoglobin gibi oksijen taşıyan proteinlerin hayati bileşenlerinden biridir. Demir $\left(\mathrm{Fe}^{2+}\right.$ ve $\left.\mathrm{Fe}^{3+}\right)$ iyonları arasındaki dönüşümden dolayı çeşitli biyolojik redoks reaksiyonları için önemli bir geçiş metalidir [2].

Türkiye'de demir eksikliği toprak ve insan nüfusu için önemli bir sorundur. Demir eksikliği, bağışıklık sistemindeki anemi ve dengesizliklerin bir nedeni olmasının yanı sıra hayvanlarda büyüme ve zihinsel gelişim sorunları ile bitkiler ve toprak için ise önemli bir beslenme problemidir.

Demir eksikliği, bitkilerin alkali toprak veya sulama suyu alanlarındaki en büyük sorunlarından biridir. En önemli bahçecilik ve tarım bitkilerinin çoğu, demir eksikliğine karşı hassastır. Demir eksikliğinin düzeltilmesi için şu anda mevcut demir içeren gübreler ya etkisizdir ya da eğer etkiliyse çok pahalıdır. Bu nedenle, etkili ancak ekonomik bir demir gübresine ihtiyaç oldukça önem arz etmektedir [3].

Bitkilerdeki var olan demir eski yapraklardan yeni yapraklara aktarılmadığı ve büyüyen organların demir ihtiyacının sürekli olarak demir alımı ile karşılanması gerektiği düşünüldügünde, bitki üretiminde toprak ve yaprak gübreleri vasıtasıyla demir eksikliğini önlemek için en önemli hususlardan birisi kullanılabilir demir içeriğinin zenginleştirilmesidir.

Yüksek pH ve bikarbonat konsantrasyonlarından kaynaklı kalkerli topraklarda yetişen bitkileri etkileyen demir eksikliği klorozu (IDC), bitkilerin ortak bir beslenme bozukluğudur [4]. Özellikle sulamayla değerlendirilen kurak ve yarı kurak bölgelerde kalkerli topraklarda demir klorozu yaygın bir problemdir. Genellikle, kireçli topraklarda, apoplastın yüksek $\mathrm{pH}$ ortamı tarafından engellenen yapraklarda ferrik şelat redüktaz tarafindan $\mathrm{Fe}$ (III)'ün $\mathrm{Fe}$ (II)'ye indirgenmesi, ancak yeterli miktarda demir'in köklerden yapraklara aktarılması ile mümkün olmaktadır [5]. Demir klorozunun yaprak fotosentetik pigment konsantrasyonlarındaki, özellikle klorofildeki azalmaya bağlı olarak ürün ve meyve kalitesinin düşmesine neden olduğu bildirilmiştir [6].

Demir klorozuna neden olan şartlar özetle; 1. Demirce fakir topraklar, 2. Kireç oranı yüksek topraklar, 3. Toprakların aşırı sulanması, 4. Aşırı miktarda ağır metaller ( $\mathrm{Mn}, \mathrm{Cu}$ ve $\mathrm{Zn}$ ) içeren topraklar, 5. Özellikle kireçli, topraklarda potasyumun noksanlığ1, 6. Nitratça zengin azotlu gübre uygulamaları, 7. Nematod ve diğer organizmalar tarafından köklerin zarar görmesi gibi birçok neden siralanabilir [7].

Demir iyonunun bitki bünyesine alınması ve bitkilerdeki demir iyonu eksikliğinin giderilmesi demirin suda çözünür formda olmasıyla mümkündür. Kalkerli topraklarda demir iyonunun 
çözünmeyen bileşiklerine $\left(\mathrm{Fe}(\mathrm{OH})_{3}, \quad \mathrm{Fe}_{2}\left(\mathrm{CO}_{3}\right)_{3}\right.$ gibi) dönüşmesi bitki tarafından bu demirin besin olarak kullanılamamasına neden olmaktadır. Demir gübrelerinin bütün katı uygulamaları arasında sentetik Fe(II) şelatları temel olarak Etilendiamin di(o-hidroksifenil asetik asit) (EDDHA) ve etilendiamin di(2-hidroksi-4metilfenil asetik asit) (EDDHMA) gibi fenolik gruplar ile poliamin-karboksilik asitlerinin yüksek pH değerlerinde suda çözünür $\mathrm{Fe}$ (II) şelatları şeklinde yaygın olarak kullanılmaktadır. $\mathrm{Bu}$ moleküller ve diğer homolog moleküller örneğin etilendi (2-hidroksi-5-sülfofenil asetik asit), 15. yüzyılda ilk kez sentezlenmiş ve daha sonra bitkilerdeki demir eksikliğini gidermek için bunların Fe (II) komplekslerinin oldukça etkili olduğu öne sürülmüştür.

Bu proje kapsamında daha ucuz olan sitrik asit ve trietanolamin gibi ligandlarla oluşturulan demir şelatının bazik pH'lardaki kararlılıkları incelenmiştir. Ülkemiz topraklarında rahatlıkla kullanılabilir özellikte demir şelatları belirlenmeye çalışılmış ve bunların ekonomik üretilebilirlikleri incelenmiştir. Bazik ortamda kararlı olan ve suda rahat çözülebilen demir-şelat formülü hazırlanıp bitkiler arasında en çok demire ihtiyaç duyan yerfıstığı bitkisi kullanılarak faydalı veya zararlı etkileri incelenmiştir.

\section{MATERYAL VE METOT}

\subsection{Materyal}

Sitrik Asit, demir sülfat heptahidrat $\left(\mathrm{FeSO}_{4} \cdot 7 \mathrm{H}_{2} \mathrm{O}\right)$, potasyum hidroksit $(\mathrm{KOH})$ ve trietanolamin bileşiklerinin tamamı yüksek saflıkta ticari olarak temin edilmiştir.

Hassas terazi olarak Ohaus Adventurer marka terazi, kurutma ve nem tayini için Elektro-mag EV-018 marka etüv, demir tayini için PerkinElmer Optima 2100DV ICP marka ICP-OES cihazı, Organik madde ve kül tayini için Nüve marka kül fırını, pH ölçümü için Hanna 210 marka pH metre ve azot tayini için Velp Scientifica marka cihazlar kullanılmıştır.

\subsection{Metod}

\subsection{1. Şelatlanmış Demir Çözelti Karışımının Hazırlanması}

Yapılan optimizasyon çalışmaları sonucunda mekanik karıştırıcılı 500 mL'lik bir balon içerisinde sırasıyla $200 \mathrm{~mL}$ su üzerine $0.1 \mathrm{~mol}$ (19.21 g) sitrik asit eklenerek çözülmüştür. Daha sonra $0.3 \mathrm{~mol}$ (16.83 g) $\mathrm{KOH}$ katı olarak parça parça dikkatli bir şeklide ilave edilmiş ve karıştırmaya devam edilmiştir. Elde edilen potasyum sitrat çözeltisi üzerine $0.1 \mathrm{~mol}(27.8 \mathrm{~g})$ $\mathrm{FeSO}_{4} .7 \mathrm{H}_{2} \mathrm{O}$ ve $0.1 \mathrm{~mol}(14.9 \mathrm{~g})$ trietanol amin eklenerek iyice karıştırılan Sitrik Asit: $\mathrm{FeSO}_{4} .7 \mathrm{H}_{2} \mathrm{O}$ : KOH: Trietanolamin 1:1:3:1 mol oranlarında koyu kahve renkli yoğun bir çözelti halinde elde edilmiştir [8]. Karışımın \%78,2'si su ve \%2'si de $\mathrm{Fe}^{2+}$ iyonu olacak şekilde çözelti hazırlanmıştır. Elde edilen çözelti aşırı koyu kahverengi olduğundan çözünmelerin daha net görülmesi ve çökeltinin olmadığının da anlaşılabilmesi için çözelti $1 / 10$ kat seyreltilmiştir. Burada hazırlanan ürünün yoğun çözelti formunun pH: 10'da kararlı olduğu belirlenmiştir. Elde edilen demir kompleksinin önerilen molekül yapısı Şekil 1'de ve 1/10 oranında seyreltme sonrası görünüm Şekil 2'de verilmiştir. Ayrıca yukarıda verilen oranlarda çalışılarak hazırlanan demir şelatının istenirse kurutulup toz halinde şelatlanmış demir kompleksi olarak $\mathrm{Fe}^{+2}$ içeriği değişmeden uzun süre saklanabilirliği de belirlenmiştir.

Karşılaştırmak amaçlı hazırlanan demir sitrat çözeltisi: Hazırlanan yeni demir şelat çözeltisi ile kıyaslanmak amaçlı tri etanol amin kullanılmadan hazırlanan $500 \mathrm{~mL}$ 'lik bir balon içerisinde sırasıyla $215 \mathrm{~mL}$ su içerisine $0.1 \mathrm{~mol}(19.21 \mathrm{~g})$ sitrik asit eklenerek çözülmüştür. Üzerine 0.3 mol (16.83 g) $\mathrm{KOH}$ katı olarak dikkatli bir şekilde parça parça ilave edilip karıștırılmıştır. Elde edilen potasyum sitrat çözeltisi üzerine trietanol amin olmaksızın $0.1 \mathrm{~mol}(27.8 \mathrm{~g}) \mathrm{FeSO}_{4} .7 \mathrm{H}_{2} \mathrm{O}$ eklenmiş ve iyice karıştırılmıştır. Sitrik Asit: $\mathrm{KOH}: \mathrm{FeSO}_{4} .7 \mathrm{H}_{2} \mathrm{O}$ karışımı 1:3:1 molar oranlarında yine koyu kahve renkli yoğun bir çözelti olarak elde edilmiştir. Karışımın \%83-84'ü su ve \%2'si Fe ${ }^{2+}$ iyonu olacak şekilde hazırlanmış ve $50 \mathrm{~mL}$ toplam hacminde 
hazırlanan çözeltinin verilen metoda uygun olarak pH dayanımı test edilmiştir.

Karşılaştırmak amaçlı hazırlanan Demir sülfat (FeSO4.7H2O) çözeltisi: Karşılaştırmak amaçlı hazırlanan $45 \mathrm{~mL}$ su içerisine $0.018 \mathrm{~mol}(5.00 \mathrm{~g})$ $\mathrm{FeSO}_{4} \cdot 7 \mathrm{H}_{2} \mathrm{O}$ eklenerek çözülmüştür. Yine \%2'si $\mathrm{Fe}^{2+}$ iyonu olacak şekilde hazırlanmış olan demir sülfat çözeltisi $\mathrm{pH}$ dayanım aralığı metoduna göre test edilmiştir.

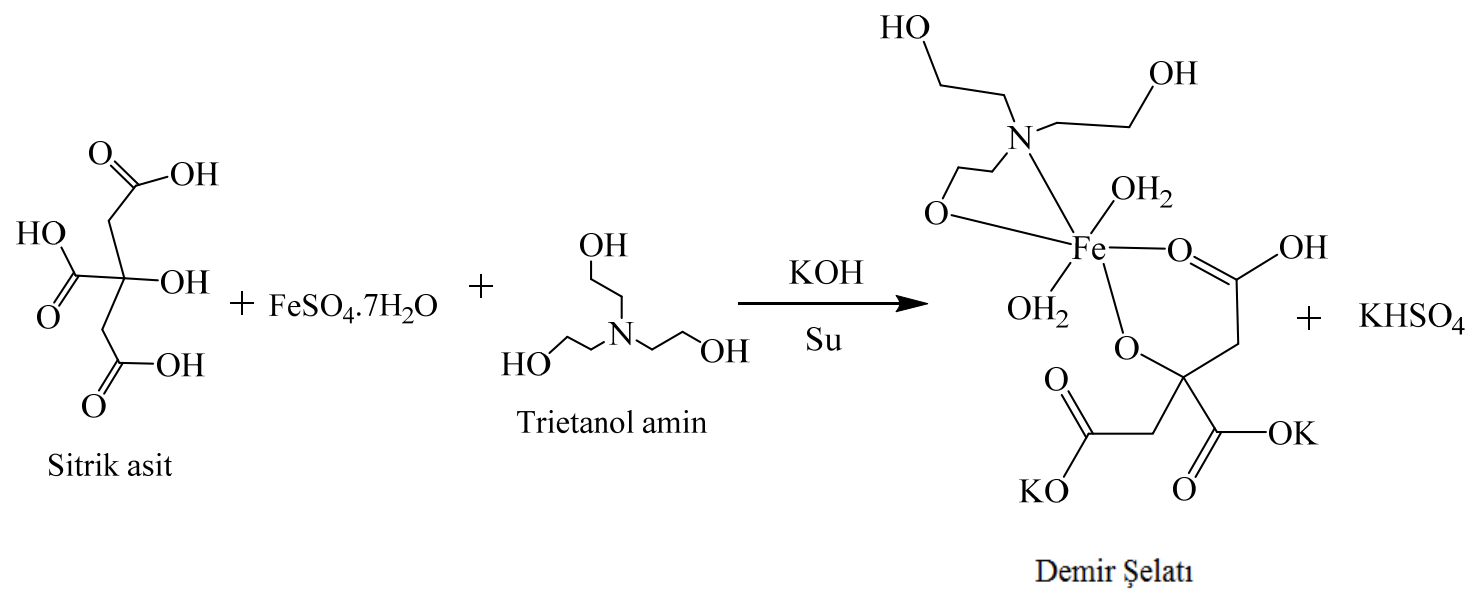

Şekil 1. Yüksek pH dayanımlı yeni demir şelatın üretim şeması
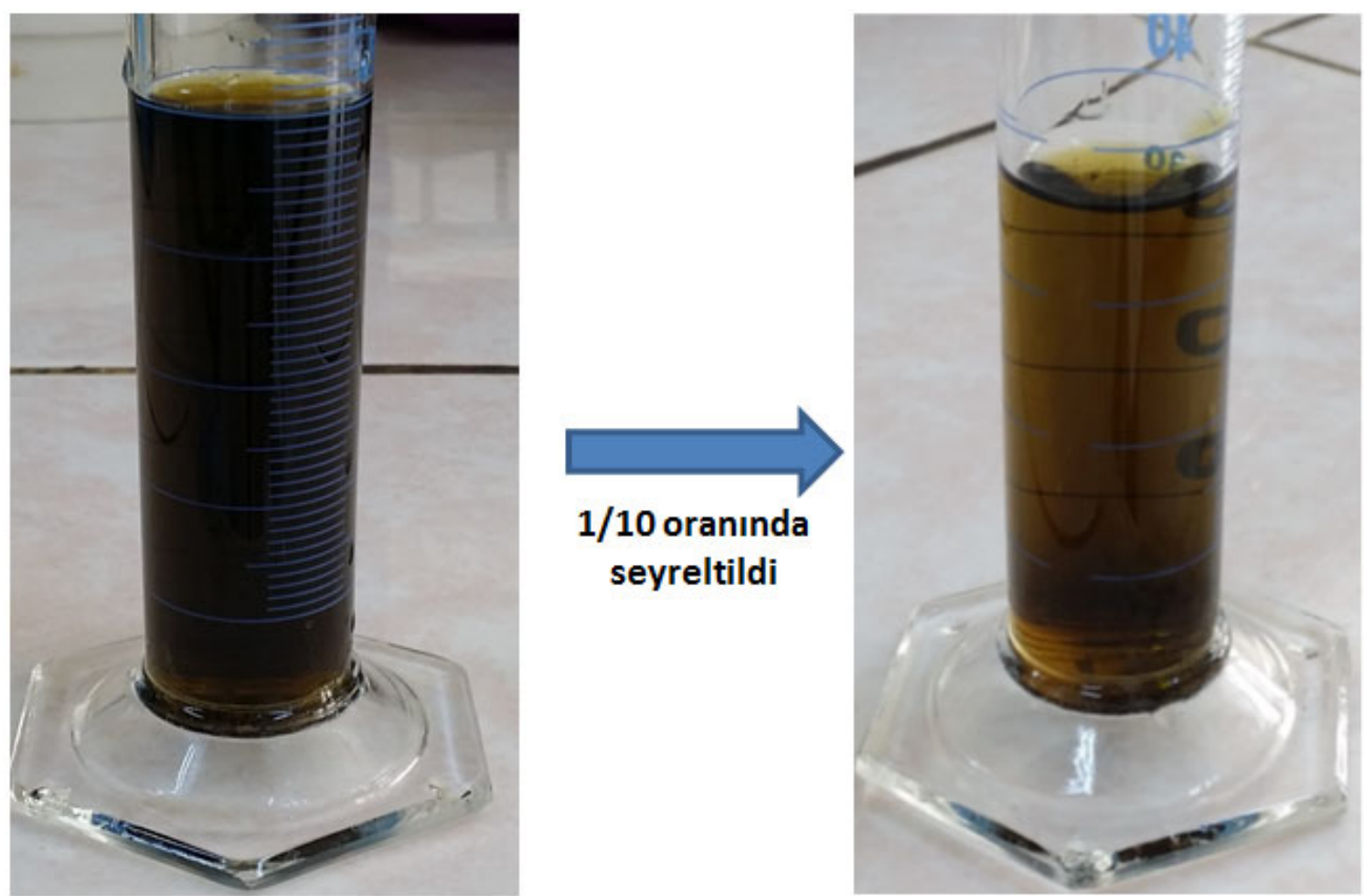

Şekil 2. $1 / 10$ oranında seyreltilerek hazırlanan çözeltide çökelmenin olmadığı ve berrak olduğu görülmektedir 


\subsubsection{Sentezlenen Demir Sitrat Şelatının Karakterizasyonunda Kullanılan Yöntemler}

\subsubsection{ICP-OES ile Toplam Demir (Fe) Analizi}

Tamamen çözünebilen şelatlanmış demir kompleksinden $0.1 \mathrm{~g}$ tartılmış ve $10 \mathrm{~mL}$ derişik nitrik asit ile tek boyunlu bir balon içerisinde 2 saat reflüks edilmiştir. Bu aşamada kompleks yapı parçalanıp içerisindeki organik bileşiklerden kurtulmak için yakma işlemi gerçekleştirilmiştir. Elde edilen asitli çözelti soğutularak ultra saflaştırılmış su ile 100 mL'lik balon jojeye süzülerek aktarılmıştır. Standart çözelti derişim aralığına göre uygun seyreltmeler yapılarak ICPOES cihazında analiz değerleri belirlenmiştir. Her analiz $3 \mathrm{kez}$ tekrarlanmış ve gerekli seyreltmeler göz önüne alınıp hesaplamaların ortalaması alınarak yüzde değerleri belirlenmiştir [9].

\subsubsection{Kjeldal ile Toplam Azot (N) Miktarı}

1-2 g numune tartılarak ve kjeldahl azot tayin cihazının tüpüne konulmuștur. Üzerine $40 \mathrm{~mL}$ salisilik asit + sülfürik asit karışımından eklenerek üzeri kapatılıp ve bir gece bekletilmiştir. Bekleme süresinden sonra numunenin üzerine $4 \mathrm{~g} \mathrm{NaS}_{2} \mathrm{O}_{3}$ eklenmiş ve 5 dakika $150{ }^{\circ} C^{\prime}$ yi geçmeyecek şekilde yakma işlemi yapılmıştır. Numune işleminden sonra üzerine Se-reaktif tablet ve 0.5$0.7 \mathrm{~g} \quad \mathrm{CuSO}_{4}$ eklenmiştir (inorganik yapılı çözünürlüğü yüksek gübrelerde $0.5 \mathrm{~g}$ tercih edilmektedir). 2 saat kadar daha yüksek isıda yakılmıştır ( $\mathrm{Bu}$ süreç spesifiktir ve numunede kristallenme gözlenene kadar yakmaya devam edilmiştir). Yanan numune soğutulup üzerine $100 \mathrm{~mL}$ saf su eklenmiş ve daha sonra numune 250 mL'ye tamamlanmıştır. Seyreltilen numune filtre edilerek süzüntüden $50 \mathrm{~mL}$ alınmıştır (Süzme işleminde süzüntünün ilk $50 \mathrm{~mL}$ 'si atılır). Hazırlanan numune Kjeldahl cihazına yerleştirilmiş ve $\% 35^{\prime}$ lik $\mathrm{NaOH}$ ile doyurulmuştur. Kjeldahl cihazına azot topladığımız erlene \%4'lük borik asitten $100 \mathrm{~mL}$ eklenmiş ve destile edilmiştir. Destile işlemi destilat $250 \mathrm{~mL}$ 'yi buluncaya kadar devam edilmiştir. Son olarak destilat $0.1 \mathrm{M} \mathrm{HCl}$ ile titre edilmiş ve gerekli seyreltme faktörleri hesaba katılarak azot miktarı belirlenmiştir.

\subsubsection{3. \% Nem}

Sabit tartıma getirilen petri kabı veya nikel kurutma kaplarının içerisine 4-5 g homojen hale getirilmiş örnekten tartılarak alınmıştır $\left(\mathrm{M}_{1}\right)$. Kurutma kabı etüve yerleştirilip etüvün sıcaklığ1 yavaş yavaş $105 \pm 2{ }^{\circ} \mathrm{C}$ 'a getirilmiştir. 3-4 saat sonunda kurutma kapları desikatöre alınıp soğuması beklenmiştir. Soğuyan kabın tartımı alınmıştır $\left(\mathrm{M}_{2}\right)$. Hesaplamalar, $\% \mathrm{Nem}=\left[\left(\mathrm{M}_{1}-\mathrm{M}_{2}\right) / \mathrm{m}\right] \times 100$ formülü kullanılarak yapılmıştır. $\quad \mathrm{M}_{1}=$ Alınan örnek ağırlığı + sabit tartıma getirilen kurutma kabının ağırlığı, $\mathrm{M}_{2}=$ Kurutulmuş örnek+ sabit tartıma getirilen kurutma kabının ağırlığı ve $\mathrm{m}=$ Alınan örneğin ağırlığ olarak simgelenmektedir.

\subsubsection{4. \% Organik Madde}

İyi temizlenmiş porselen kroze $550{ }^{\circ} \mathrm{C}$ 'de sabit tartıma getirilerek krozenin darası kaydedilmiştir. Sabit tartıma getirilen kroze içerisine numuneden 3-5 g örnek tartılıp sicaklığı $550{ }^{\circ} \mathrm{C}$ 'a ayarlanan kül firınında 7-8 saat bekletilmiştir. $\mathrm{Bu}$ süre sonunda krozeler desikatöre alınarak oda sıcaklığına kadar soğuması beklenmiş ve soğuyan krozenin tartımı alınarak hesaplamalar yapılmıştır. $\%$ Kül $=\left[\left(\mathrm{M}_{2}-\mathrm{M}_{1}\right) / \mathrm{m}\right] \times 100$ formülü kullanılarak hesaplanmıştır. $\mathrm{M}_{2}=$ Yakmadan sonraki kroze+kül ağırlığ $1, \quad \mathrm{M}_{1}=$ Sabit tartıma getirilen krozenin ağırlığ 1 ve $m=A$ lınan örnek ağırlığ 1 olarak simgelenmiştir. $\%$ Organik=100-(\%Kül+\%Nem) formülü kullanılarak hesaplanmaktadır.

\subsubsection{5. pH Dayanım Aralığının Belirlenmesi}

\%2 $\mathrm{Fe}^{2+}$ iyonu içeren demir şelat çözeltisinin 50 $\mathrm{mL}$ 'si bir behere eklenerek önceden hazırlanmış olan \%4'lük $\mathrm{NaOH}$ çözeltisi damla damla ilave edilip iyice karıştırılmıştır. Çökelme gözlenene kadar eklemeye devam edilmiş ve çökelmenin oluştuğu pH kaydedilmiştir. Aynı işlemler $\% 2 \mathrm{Fe}^{2+}$ iyonu içeren $\mathrm{FeSO}_{4} .7 \mathrm{H}_{2} \mathrm{O}$ ve Sitrik Asit: $\mathrm{KOH}$ : $\mathrm{FeSO}_{4} .7 \mathrm{H}_{2} \mathrm{O}: 1: 3: 1 \mathrm{~mol}$ oranlarında hazırlanan 50 mL'lik çözeltiler içinde tekrarlanmıştır [10]. Tüm veriler Şekil 1-3'de görülmektedir. 


\subsubsection{Yerfıstığı Üzerine Demir Şelatının Etkisi}

Deneme öncesi toprak analizi yapılmış ve Çizelge 1'de verilmiş olan Karaburun toprak serisi kullanılmıştır. Yapılan çalışmada 4 ayrı demir uygulaması 3 tekrarlı olarak gerçekleştirilmiştir. Test bitkileri olarak NC-7 ve ÇOM yerfıstığı çeşitleri kullanılmıştır. Deneme sera koşullarında plastik saksılarda yürütülmüştür. Her saksıya $4 \mathrm{~mm}$ 'lik elek kullanılarak elenmiş $8 \mathrm{~kg}$ toprak konulmuştur. Temel gübreleme olarak her saksıya 100 ppm azot içeren amonyum sülfat ve 125 ppm fosfor içeren TSP bileşikleri kullanılmıştır.
Saksılara demir kaynağı olarak demir şelat çözeltisi, demir sitrat ve demir sülfat 20 ppm Fe ${ }^{2+}$ iyonu içerecek şekilde uygulanmıştır. Ayrıca demir sülfat + çiftlik gübresi (160 g/saksı) ve demir sülfat + kompost (160 g/saks1) uygulanmıştır. Başlangıçta her saksıya 8 adet yer fistığı ekilmiş ve çimlenmeden sonra 4 adet olacak şekilde seyreltilmiştir. Saksılar saf su ile sulanmıştır. Ekim işlemi 22.03.2018 tarihinde yapılıp hasat işlemi ise 15.05.2018 tarihinde yapılmıştır. Deneme deseni Çizelge 3'de verilmiştir.

Çizelge 1. Deneme alanı toprağının ekim öncesi bazı fiziksel ve kimyasal analiz sonuçları

\begin{tabular}{|c|c|c|c|c|c|c|c|c|c|c|}
\hline \multirow{2}{*}{$\begin{array}{c}\text { Toprak } \\
\text { Serisi }\end{array}$} & \multirow{2}{*}{$\begin{array}{c}\text { Tekstür } \\
\text { Sınıfı }\end{array}$} & $\mathbf{P}_{2} \mathbf{O}_{5}$ & $\mathrm{~K}_{2} \mathrm{O}$ & \multirow{2}{*}{$\begin{array}{c}\text { Organik } \\
\text { Madde } \\
(\%)\end{array}$} & \multirow{2}{*}{ pH } & \multirow{2}{*}{$\begin{array}{c}\mathrm{CaCO}_{3} \\
(\%)\end{array}$} & \multirow{2}{*}{$\begin{array}{l}\text { Tuz } \\
(\%)\end{array}$} & $\mathrm{Fe}$ & $\mathbf{Z n}$ & $\mathbf{C u}$ \\
\hline & & kg & & & & & & \multicolumn{3}{|c|}{$\mathrm{mg} / \mathrm{kg}$} \\
\hline Karaburun & $\mathrm{CL}$ & 1.87 & 62 & 1.3 & 7.63 & 51.2 & 0.025 & 6.02 & 0.212 & 0.53 \\
\hline
\end{tabular}

\section{ARAŞTIRMA BULGULARI VE TARTIŞMA}

Elde edilen yeni tip demir şelatının karakterizasyonunda kullanilan ICP-OES ile toplam $\mathrm{Fe}$ ve $\mathrm{K}^{+}$analizi, Kjeldal ile toplam Azot (N), \% Nem, \% organik madde ve $\mathrm{pH}$ dayanım aralığının belirlenmesi yöntemlerinin sonuçları değerlendirildiğinde elde edilen veriler aşağıdaki Çizelge 2'de görülmektedir. Deneysel sonuçlar teorik verilerle uyum içerisinde olduğu görülmektedir.

Çizelge 2. Şelatlanmış demir sitrat çözelti analizi

\begin{tabular}{|l|c|}
\hline Analiz cinsi: & $\begin{array}{c}\text { Deneysel/Teorik \% } \\
\text { Değerler }\end{array}$ \\
\hline $\mathrm{Su}$ & $76.9 / 78.2$ \\
\hline Toplam Fe & $1.96 / 2.00$ \\
\hline $\mathrm{K}_{2} \mathrm{O}$ & $4.85 / 5.06$ \\
\hline Toplam N & $0.57 / 0.50$ \\
\hline Organik Madde & $10.22 / 8.92$ \\
\hline $\mathrm{pH}$ & 6.71 \\
\hline $\mathrm{pH}$ Dayanım Aralığ 1 & $10-11$ \\
\hline
\end{tabular}

\section{1. pH Kararlılık Değerlendirilmesi}

$\% 2 \mathrm{Fe}^{2+}$ iyonu içeren ve pH'sını 6.71 olarak belirlediğimiz yüksek $\mathrm{pH}$ dayanıml yeni tip hazırlanan demir şelat çözeltisinin $50 \mathrm{~mL}$ 'si bir behere alınmıştır. $\mathrm{Bu}$ çözelti üzerine \%4'lük $\mathrm{NaOH}$ çözeltisi damla damla ilave edilerek karıştırılmıştır. $\quad \mathrm{pH}$ : 10.02 'de çökelme gözlenmediği kaydedilmiştir.

Trietanol amin olmaksızın 1:3:1 molar oranında Sitrik Asit: $\mathrm{KOH}$ : $\mathrm{FeSO}_{4} .7 \mathrm{H}_{2} \mathrm{O} \quad 50 \mathrm{~mL}$ 'lik çözeltiler hazırlanmış ve ilk pH'sı 4.28 olarak belirlenmiştir. Daha sonra çözelti üzerine $\mathrm{NaOH}$ çözeltisi damla damla eklenerek çökelmenin oluştuğu pH aralığı 8.50-8.85 olarak belirlenmiştir.

Aynı işlemler ticari olarak alınan katı $\mathrm{FeSO}_{4} .7 \mathrm{H}_{2} \mathrm{O}$ 'ın çözünmesi sonrası pH'sı 2.9 olarak belirlenen ve $\% 2 \mathrm{Fe}^{2+}$ içeren $50 \mathrm{~mL}$ 'lik $\mathrm{FeSO}_{4} \cdot 7 \mathrm{H}_{2} \mathrm{O}$ çözeltisi hazırlanmıştır. 4-5 damla sonra $\mathrm{NaOH}$ çözeltisinin eklenmesi ile çökelmenin pH 3.23'de oluştuğu kaydedilmiştir. Bu değerler ışığında sentezlenmiş olan yeni tip demir şelatının pH:10 değerlerinde çökelme olmadan suda çözünür formda bulunduğu görülmüştür. Tüm veriler Şekil 3-5'de görülmektedir. 


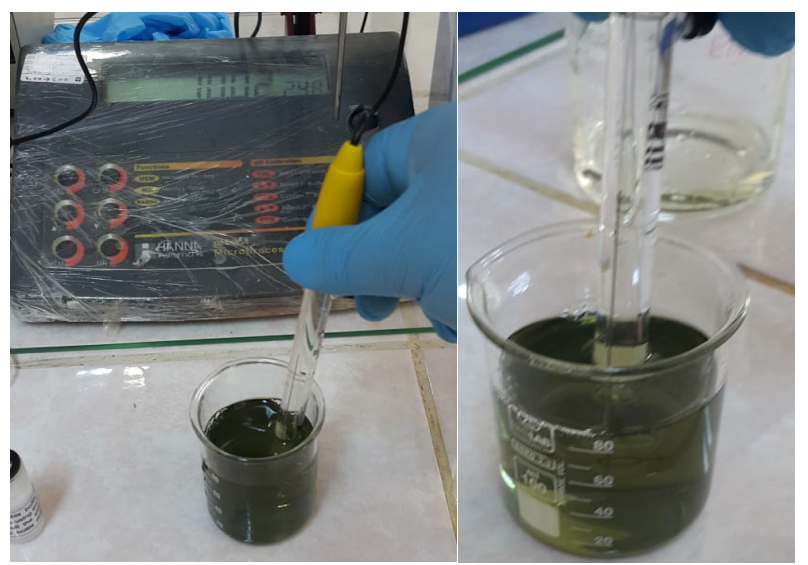

Şekil 3. Demir şelat çözeltisinin pH dayanımının incelenmesi

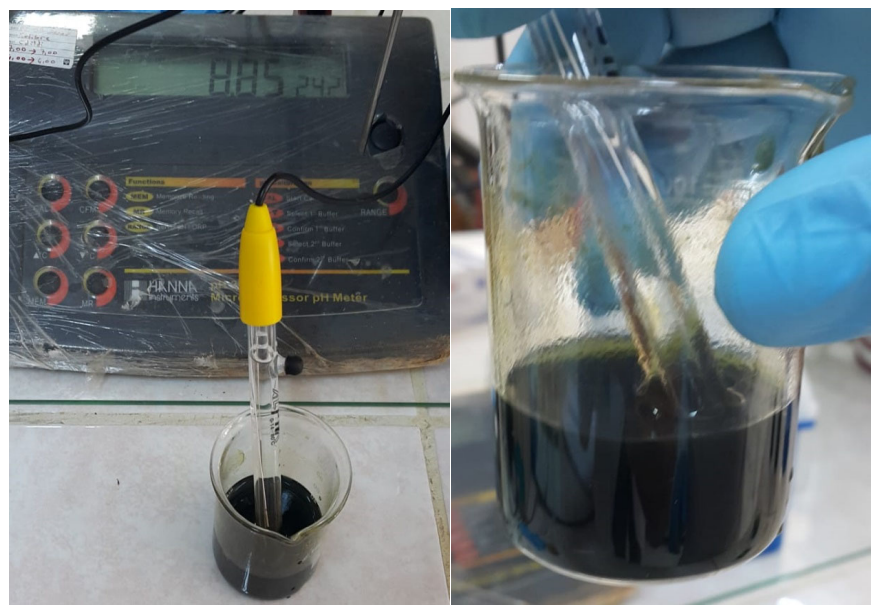

Şekil 4. Trietanol amin eklenmeden hazırlanan demir sitrat çözeltisinin $\mathrm{pH}$ dayanımının incelenmesi

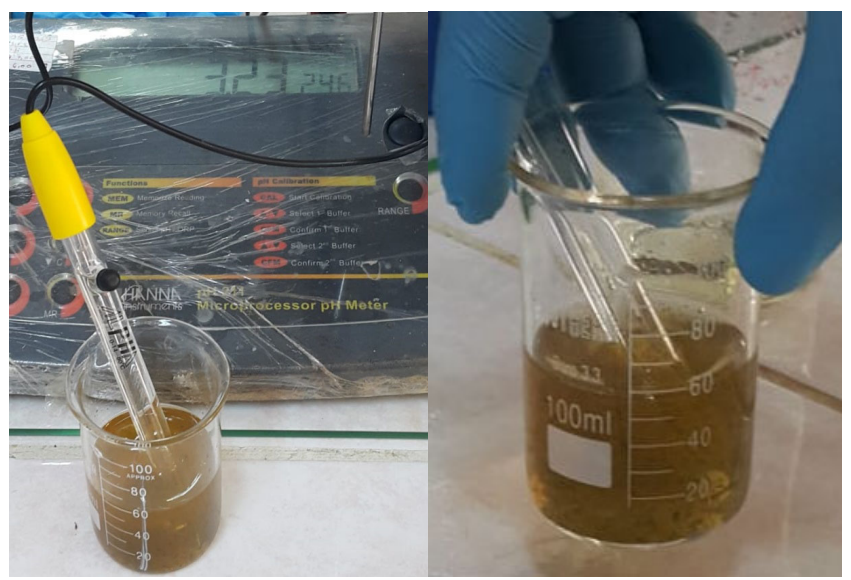

Şekil 5. Ticari olarak satın alınan ve suda doğrudan çözülerek hazırlanan demir sülfat çözeltisinin pH dayanımının incelenmesi 


\subsection{Hazırlanan Demir Şelatının Yerfistığı Üzerine Uygulamalarının Değerlendirilmesi}

Yapılan fenolojik gözlemlerde çıkıştan 1 ay sonra NC-7 çeşidinde kontrol saksılarında (demir uygulanmamıș) șiddetli kloroz görülmeye başlanmış ancak bu durum CCOM çeşidinde gözlenmemiştir. Demir şelatlı çözelti uygulanan saksılarda sadece 1-2 bitkide hafif kloroz gözlenmiş ve demir sitrat çözeltisini (trietanol amin kullanılmadan) uyguladığımızda daha fazla sayıda bitki de kloroz gözlenmiștir. Demir sülfat tek başına uygulanmıș ancak etkili olmadığından dahil edilmemiştir. Ancak demir sülfat + kompost ve demir sülfat + çiftlik gübresi ile karıştırılarak uygulanan saksılarda ise hafif kloroz gözlenmiş ve bu durum hasata kadar devam etmiștir. Demir şelat çözeltisi uygulanan bitkilerin diğer demir uygulamalarına göre daha iyi geliştikleri belirlenmiş ve bu gelişim Şekil 6'da ortaya konulmuştur.

Çizelge 3. Yer fistığına ait deneme deseni

\begin{tabular}{|l|l|c|}
\hline Çeşit & Uygulamalar & \multicolumn{1}{|c|}{ Saksı No } \\
\hline \multirow{4}{*}{ NC-7 } & Kontrol & 1 \\
\cline { 2 - 3 } & Demir Şelatı & 2 \\
\cline { 2 - 3 } & Demir Sitrat & 3 \\
\cline { 2 - 3 } & Demir Sülfat+ Kompost & 4 \\
\cline { 2 - 3 } & Demir Sülfat +Hayvan gübresi & 0 \\
\hline \multirow{5}{*}{ ÇOM } & Kontrol & 1 \\
\cline { 2 - 3 } & Demir Şelatı & 2 \\
\cline { 2 - 3 } & Demir Sitrat & 3 \\
\cline { 2 - 3 } & Demir Sülfat+ Kompost & 4 \\
\cline { 2 - 3 } & Demir Sülfat +Hayvan gübresi & \multicolumn{1}{|c|}{} \\
\hline
\end{tabular}

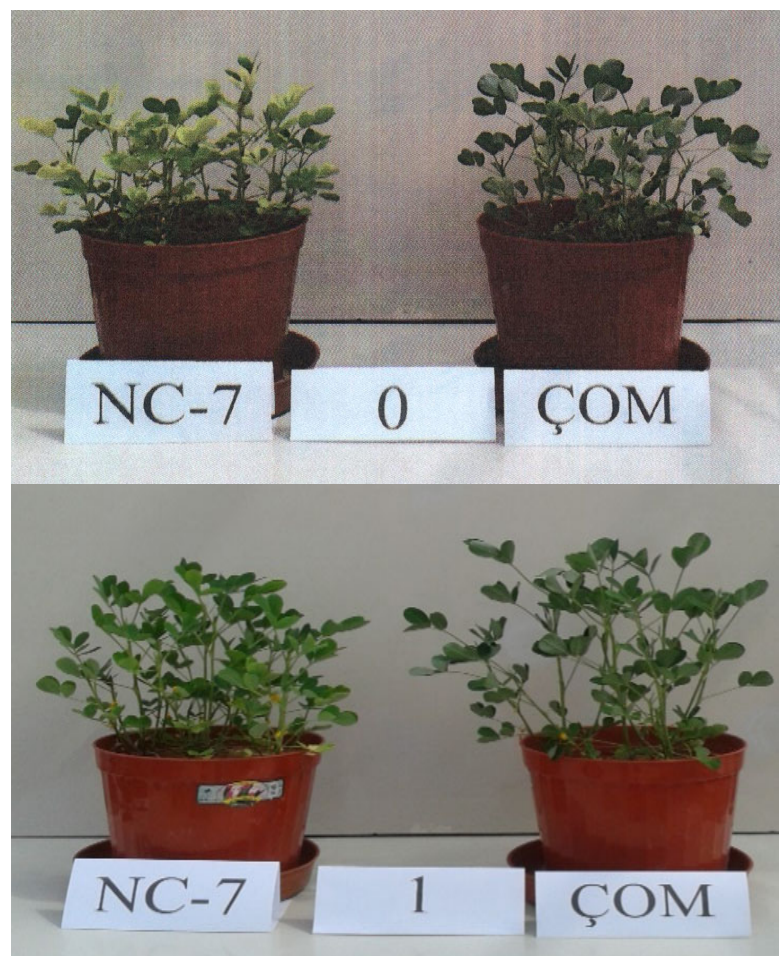




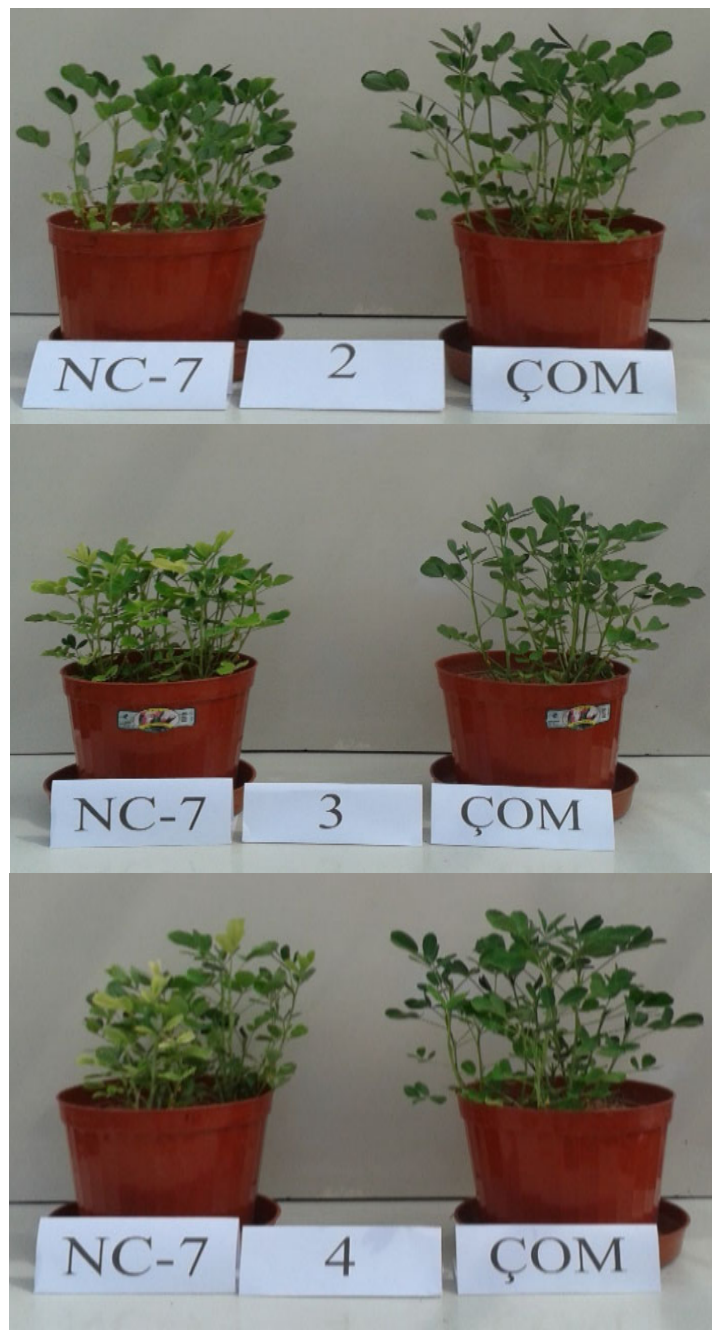

Şekil 6. Saksılarda NC-7 ve ÇOM yerfıstığı çeşitlerinde demir denemeleri

\section{SONUC}

$\mathrm{Bu}$ çalışmada, yüksek $\mathrm{pH}$ dayanımlı yeni tip demir şelat çözeltisi güçlü şelat ajanı olarak seçilen sitrik asit ve tri etanol amin kullanılarak hazırlanmıştır. Analitik ve spektroskopik analizler yapılarak elde edilen demir şelat çözeltisinin bileşenleri belirlenmiştir. Türkiye toprakları yüksek alkali özellikli olduğunda elde edilen demir şelat çözeltisinin ve bu çözeltiyi oluşturan demir sülfat çözeltisi ile demir sitrat kompleksinin (trietanolamin olmadan) maksimum $\mathrm{pH}$ dayanımları incelenmiştir. $\mathrm{pH}$ dayanımları karşılaştırıldığında elde edilen demir şelat çözeltisinin pH:10'da içerisindeki şelat ajanlarının demir iyonunun çökelmesini engelleyecek kadar güçlü demir iyonuna koordine olduğunu göstermiştir. Şelatlanmadan kullanılan demir sülfat çözeltisinin pH'daki çok küçük değişimlerde dahi çökelme göstermiştir. Sadece sitrik asit ile şelatlandığında ise $\mathrm{pH}$ dayanımının $8.5-8.85$ aralığında çökme gözlemlendiği ve en yüksek pH değerinde kararlı olarak kalabilen optimum çözelti formunun hazırlanmış olduğu belirlenmiştir. Yüksek pH aralığındaki kararlılığı belirlenen yeni tip demir şelat çözeltisinin NC-7 ve ÇOM yerfistığı çeşitlerinin büyümesi üzerine etkileri incelenmiş ve demir şelat çözeltisi kullanıldığında 
demir eksikliği kloroz oluşumu diğer kullanılmadığı denemelere göre önemli ölçüde az görüldügü belirlenmiş̧tir.

\section{TEŞEKKÜR}

$\mathrm{Bu}$ çalışmaya yaptı̆̆ katkılardan dolayı "Çukurova Üniversitesi Ziraat Fakültesi Toprak Bölümü Emekli Öğretim Üyesi Prof. Dr. Zülküf KAYA'ya teşekkürü bir borç biliriz.

\section{KAYNAKLAR}

1. Valko, M., Morris, H., Cronin, M.T., 2005. Metals, Toxicity and Oxidative Stress. Curr. Med. Chem., 12(10), 1161-1208.

2. Jaishankar, M., Tseten, T., Anbalagan, N., Mathew, B.B., Beeregowda, K.N., 2014. Toxicity, Mechanism and Health Effects of Some Heavy Metals.; Interdiscip Toxicol. 7(2), 60-72.

3. Reed, D.W., Lyons, C.G., McEachern, G.R., 1988. Field Evaluation of Inorganic and Chelated Iron Fertilizers as Foliar Sprays and Soil Application. Journal of Plant Nutrition, 11(6-11), 1369-1378.

4. Chakraborty, B., Singh, P.N., Kumar, S., Srivastava, P.C., 2014. Uptake and Distribution of Iron from Different Iron Sources Applied as Foliar Sprays to Chlorotic Leaves of Low-Chill Peach Cultivars. Agric. Res. 3(4), 293-301.

5. Chen, H., Hu, Z., Li, X., Zhang F., Chen J., Zhang, M., 2016. Iron Fertilizers Applied to Calcareous Soil on the Growth of Peanut in a Pot Experiment. Arch. Agron. Soil Sci. 62(12), 1753-1764.

6. Abadía, J., Vázquez, S., Rellán-Álvarez, R., EI-Jendoubi, H., Abadía, A., ÁlvarezFernández, A., López-Millán, AF., 2011. Towards a Knowledge-based Correction of Iron Chlorosis. Plant Physiol Biochem. 49, 471-482.

7. Horuz, A., Korkmaz, A., Akınoğlu, G., Boz, E., 2016. Bitkilerde Demir Klorozunun Nedenleri ve Giderilme Yöntemleri. Toprak Bilimi ve Bitki Besleme Dergisi 4(1), 32-42.

8. Hernandez-Apaolaza, L.H., Garciä-Marco, S., Nadal, P., Lucena, J.J., 2006. Structure and
Fertilizer Properties of Byproducts Formed in the Synthesis of EDDHA. J. Agric. Food Chem., 54, 4355-4363.

9. Ferrari, V., Taffarel, S.R., Espinosa-Fuentes, E., Oliveira, M.L.S., Saikia, B.K., 2019. Oliveira, L.F.S., Chemical Evaluation of ByProducts of the Grape Industry as Potential Agricultural Fertilizers. Journal of Cleaner Production. 208, 297-306.

10. De Luca, A., Dantas, R.F., Esplugas, S., 2014. Assessment of Iron Chelates Efficiency for Photo-fenton at Neutral $\mathrm{pH}$. Water Research. $61,232-242$. 